\title{
Diaphragm electromyogram in infants with abdominal wall defects and congenital diaphragmatic hernia
}

\author{
Z. Kassim**\#, C. Jolley*,", J. Moxham**, A. Greenough**\# and G.F. Rafferty*,\#,
}

ABSTRACT: Measurement of the diaphragm electromyogram (EMGdi) elicited by phrenic nerve stimulation could be useful to assess neonates suffering from respiratory distress due to diaphragm dysfunction, as observed in infants with abdominal wall defects (AWD) or congenital diaphragmatic hernia (CDH). The study aims were to assess the feasibility of recording EMGdi using a multipair oesophageal electrode catheter and examine whether diaphragm muscle and/or phrenic nerve function was compromised in AWD or CDH infants.

Diaphragm compound muscle action potentials elicited by magnetic phrenic nerve stimulation were recorded from 18 infants with surgically repaired AWD $(n=13)$ or $C D H(n=5)$, median (range) gestational age 36.5 (34-40) weeks. Diaphragm strength was assessed as twitch transdiaphragmatic pressure (TwPdi).

One AWD patient had prolonged phrenic nerve latency (PNL) bilaterally (left $9.31 \mathrm{~ms}$, right $9.49 \mathrm{~ms}$ ) and two CDH patients had prolonged PNL on the affected side (10.1 ms and $10.08 \mathrm{~ms})$. There was no difference in left and right TwPdi in either group. PNL correlated significantly with TwPdi in CDH ( $r=0.8 ; p=0.009)$.

Oesophageal EMG and magnetic stimulation of the phrenic nerves can be useful to assess phrenic nerve function in infants. Reduced phrenic nerve conduction accompanies the reduced diaphragm force production observed in infants with $\mathrm{CDH}$.

KEYWORDS: Congenital diaphragmatic hernia, diagnostics, diaphragm, electromyography, phrenic nerve, respiratory muscle testing

I nfants may suffer respiratory distress in the neonatal period due to diaphragm or global respiratory muscle dysfunction which can occur for many reasons [1]. Surgical procedures [2], trauma [3], atrophy and remodelling from reduced activity [4], and medications are recognised to produce respiratory muscle weakness [5]. Abnormal phrenic nerve and/or respiratory muscle function can impair antenatal lung growth [6] and delay or prevent weaning and extubation from mechanical ventilation [7]. Conversely, identifying infants who would benefit from diaphragm plication can facilitate weaning from mechanical ventilation and prevent complications of prolonged ventilation [8].

Radiological and ultrasonographic methods of diagnosing respiratory muscle dysfunction are widely used but can be unreliable, particularly in ventilated patients [2]. Maximal inspiratory transdiaphragmatic and airway pressures during crying have been used to estimate diaphragm strength in infants [9] but the technique is effort dependent and the results can be submaximal and variable.

Measurement of airway and/or transdiaphragmatic pressures elicited by transcutaneous phrenic nerve stimulation allows diaphragm muscle function to be assessed directly and independently of volition [10]. Recording the evoked diaphragm electromyogram (EMGdi) response allows phrenic nerve function to be assessed [2] The electrical and force responses, when used in combination, allow complete assessment of the neuro-muscular unit.

Multipair oesophageal electrode catheters have been developed [11] that provide potentially clearer, less contaminated signals than those from surface electrodes $[11,12]$ and the technique is less invasive than needle electrodes. In addition, the phrenic nerve latency (PNL) and compound muscle action potential (CMAP) amplitude are reproducible as the catheter can be positioned accurately at the electrically active centre of the diaphragm [13].

\section{AFFILIATIONS}

${ }^{*}$ Division of Asthma, Allergy and Lung Biology, King's College London,

Depts of \#Child Health, and

'Respiratory Medicine, King's

College London School of Medicine at Guy's, King's College and St

Thomas' Hospitals, London, UK

\section{CORRESPONDENCE}

G.F. Rafferty

Dept of Child Health

4th Floor Golden Jubilee Wing

King's College London School of

Medicine

Bessemer Road

London

SE5 9PJ

UK

E-mail: gerrard.rafferty@kcl.ac.uk

Received:

Jan 152010

Accepted after revision:

April 272010

First published online:

June 012010 
We have previously demonstrated diaphragm dysfunction in infants with abdominal wall defects (AWD) or congenital diaphragmatic hernia $(\mathrm{CDH})$ [6], although the underlying aetiology could not be determined. Our aims, therefore, were to assess the feasibility of recording the EMGdi elicited by magnetic stimulation of the phrenic nerves (MSPN) using an oesophageal electrode catheter in infants with AWD or $\mathrm{CDH}$, and determine whether it was muscle and/or nerve function that was compromised in these patients.

\section{METHODS}

Infants with $\mathrm{CDH}$ or AWD who had been surgically repaired at least 1 week previously were eligible for entry into this study. The study was approved by the King's College Hospital NHS Research Ethics Committee (London, UK) and the parents of all the infants who participated in the study gave informed, written consent.

Phrenic nerve stimulation was performed once the $\mathrm{CDH}$ and AWD infants no longer required either mechanical ventilation or continuous positive airways pressure. EMGdi was recorded from the crural diaphragm using a multipair oesophageal electrode catheter (fig. 1). The electrode catheter consisted of seven consecutive recording electrode coils (electrode one being most proximal); each coil was $2.5 \mathrm{~mm}$ long with a $5 \mathrm{~mm}$ gap between adjacent recording electrodes. Four electrode pairs were formed (1-3, 2-4, 3-5 and 4-6) with an interelectrode distance of $1.2 \mathrm{~cm}$ within a recording pair. The upper seventh electrode was the earth. The catheter had the same diameter as a 7-French gauge nasogastric feeding tube and was introduced orally or nasally. The electrode was positioned close to the crus of the diaphragm at the electrically active centre. Evoked EMGdi signals were amplified (Pclab-3808 Biomedical amplifier; Guangzhou Yinghui Medical, Guangdon, China), acquired at a sampling frequency of $10 \mathrm{kHz}$ (Powerlab 16s analogue-to-digital converter; ADInstruments Pty Ltd, Castle Hill, Australia) and displayed in real time on a computer (iMac; Apple Computer Company, Cupertino, CA, USA) running Chart software (version 5.4; ADInstruments Pty Ltd).

Anterolateral magnetic stimulation (AMS) was performed using a $90 \mathrm{~mm}$, circular coil (Magstim Co, Whitland, UK) and a high-power magnetic stimulator (Magstim 200; Magstim Co). A section of the face of the stimulating coil was placed over the phrenic nerve on the anterolateral aspect of the neck at the posterior border of the sternomastoid muscle at the level of the cricoid cartilage.

Diaphragm force production was assessed by measurement of the maximum inspiratory mouth pressure $(\mathrm{c} P \mathrm{I}, \mathrm{max})$ generated during crying against an occlusion and the transdiaphragmatic pressure $(P \mathrm{di})$ produced by unilateral magnetic stimulation of

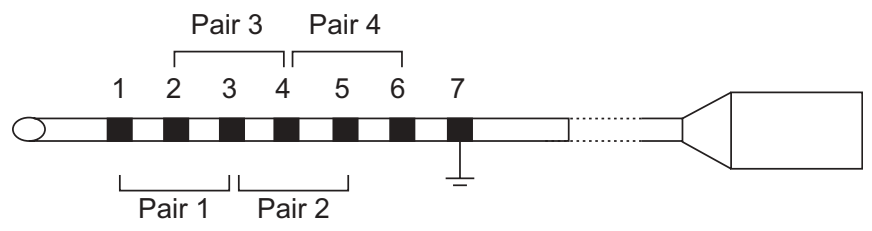

FIGURE 1. Diagrammatic representation of the oesophageal electromyogram catheter showing the arrangement of electrode pairs. the phrenic nerves (twitch $P$ di $(T w P d i))$ [10]. Oesophageal (Poes) and gastric (Pgas) pressures were measured using a dualpressure transducer tipped catheter (Gaeltec, Dunvegan, Isle of Skye, UK) and associated amplifier (Gaeltec). The two pressure transducers were $5 \mathrm{~cm}$ apart with the lower transducer $0.1 \mathrm{~cm}$ from the catheter tip. The catheter was introduced nasally or orally and positioned so that the upper transducer lay in the lower third of the oesophagus to measure intrathoracic pressure and the lower transducer was in the stomach to measure abdominal pressure.

Airflow was measured using a pneumotachograph (Mercury F10L; GM Instruments, Kilwinning, UK) attached to a facemask placed over the infant's nose and mouth and connected to a differential pressure transducer (MP45, range $\pm 2 \mathrm{~cm} \mathrm{H}_{2} \mathrm{O}$; Validyne Engineering Corp, Northridge, CA, USA). The total dead space of the pneumotachograph and facemask in situ was approximately $4.5 \mathrm{~mL}$. Airway pressure $(P a w)$ was measured from a side port of the pneumotachograph using a differential pressure transducer (MP45, range $\pm 100 \mathrm{~cm} \mathrm{H}_{2} \mathrm{O}$; Validyne Engineering Corp) and the signals from both the flow and airway pressure transducers were amplified (CD 280; Validyne Engineering Corp). The signals from all pressure transducers were recorded and displayed in real time on a computer running an application written with Labview software (National Instruments, Austin, TX, USA) with $100 \mathrm{~Hz}$ analogue-to-digital sampling (DAQ 16XE-50; National Instruments). Pdi was obtained by digital subtraction of Poes from $P$ gas by the data acquisition software.

Lung volume was assessed by measurement of functional residual capacity (FRC) using a helium gas dilution technique (Series 7700; Equilibrated Biosystems Inc, Melville, NY, USA), as described in detail previously [6]. Infants rebreathed a mixture of helium $(\mathrm{He})$ and oxygen $\left(\mathrm{O}_{2}\right)$ via a facemask until equilibration of $\mathrm{He}$ occurred. FRC was corrected for $\mathrm{O}_{2}$ consumption $\left(7 \mathrm{~mL} \cdot \mathrm{kg}^{-1} \cdot \mathrm{min}^{-1}\right)$ [14] and body temperature, ambient pressure, saturated with water vapour conditions expressed as the mean of paired measurements related to body weight. The coefficient of repeatability of FRC measurements in spontaneously breathing infants was $3.9 \mathrm{~mL} \cdot \mathrm{kg}^{-1}$ with a median (range) FRC in term infants of $30(24-36) \mathrm{mL} \cdot \mathrm{kg}^{-1}$ [6].

\section{Protocol}

The infants were studied in the supine position at least $1 \mathrm{~h}$ after a feed. None of the infants was sedated at the time of measurement. The EMG electrode catheter was introduced and positioned at the electrically active centre of the diaphragm by comparing the size and polarity of the diaphragm CMAP elicited by unilateral AMS (uAMS) such that the CMAP recorded from electrode pairs 1-3 and 3-5 were of equal amplitude but opposite polarity. The phrenic nerve was stimulated immediately following a breath at the end of expiration. The point of end expiration was judged by careful observation of the infant's ribcage and abdominal movement. At least 10 stimulations at maximum stimulator output were made on each side and the mean PNL and CMAP amplitude recorded. The normal range for PNL in this age group was taken as 2.9-9.1 ms [15] The supramaximality of the stimuli was assessed by examining the mean CMAP amplitude and PNL over the range 80, 85, 90, 95 and 100\% of stimulator 
output, delivered in random order. Five to 10 stimulations were obtained at each power setting.

The EMG catheter was then removed and the pressure catheter inserted and accurately positioned to ensure reliable measurement of Pdi. Correct positioning of the oesophageal transducer was checked by comparing Poes to Paw during a temporary occlusion of the airway. The face mask and pneumotachograph were placed over the infant's nose and mouth and the distal end of the pneumotachograph occluded. The oesophageal transducer was confirmed to be correctly sited when Poes was 90-110\% of Paw [16]. The gastric transducer was assumed to be correctly sited when there were positive pressure swings during inspiration.

End expiratory Poes was used as an indicator of lung volume relative to FRC and magnetic stimulation performed when Poes was at its resting baseline FRC value. The data are reported as the mean of at least five satisfactory twitches. Sleep state was not formally assessed, but infants were only studied during periods of quiet sleep when rapid eye movements and gross body movements were absent or when awake. To avoid twitch potentiation of the diaphragm, there was a period of $10 \mathrm{~min}$ of quiet breathing before stimulation was commenced and at least $20 \mathrm{~s}$ elapsed between each twitch.

To measure $c P I$,max the facemask was held firmly over the infant's nose and mouth during crying. The airway was occluded at end expiration, which is at the end of a crying effort. The infants were observed for evidence of chest wall distortion during occlusions and none was witnessed. The timing of the occlusions was determined by observation of the real-time display of the flow signal. $\mathrm{c} P \mathrm{I}$,max was measured from the pressure changes during crying. Two or three sets of five or more occlusions, giving at least 10 airway occlusions, were performed and the maximum $c P$ I,max achieved for an individual noted.

\section{Statistical analysis}

Group data are expressed as median (range). Comparisons between left and right PNL, CMAP amplitude and TwPdi and between AWD and $\mathrm{CDH}$ patients were performed using Kruskal-Wallis ANOVA with post hoc testing performed using Dunn's correction for multiple comparisons. Differences in gestational age, birthweight and $c P$ I,max between AWD and $\mathrm{CDH}$ patients were assessed using the Mann-Whitney test for unpaired data, while the overall effect of diaphragmatic hernia on PNL and CMAP amplitude in the $\mathrm{CDH}$ patients was assessed using Wilcoxon signed rank test for paired data. Spearman's correlation analysis was used to examine the relationship between left and right PNL and CMAP amplitude and TwPdi. The mean within-subject coefficient of variation was calculated for left and right PNL and CMAP amplitude.

\section{RESULTS}

18 infants, median (range) gestational age 37 (39-40) weeks and birthweight 2.66 (1.6-3.51) kg with either AWD (gastroschisis $(n=11)$ or exomphalos $(n=2))$ or $\mathrm{CDH}(n=5$; four left-, one right-sided defect, all posterolateral), which had been surgically repaired at least one week previously were studied. All of the infants with surgically correctable anomalies had been diagnosed antenatally by 20 weeks of gestation. All were delivered, underwent surgical repair and received intensive care at King's College Hospital, London.

Oesophageal EMG, pressure measurement and magnetic stimulation of the phrenic nerves were well tolerated by all the infants studied. A representative recording from one patient of the CMAP elicited by unilateral phrenic nerve stimulation is given in figure 2. Measurements of right PNL, diaphragm CMAP amplitude and TwPdi were obtained in all patients while measurements of left PNL, diaphragm CMAP amplitude and TwPdi were not performed in two patients with AWD due to equipment malfunction. The median (range) FRC was 24.0 (18.7-28.1) $\mathrm{mL} \cdot \mathrm{kg}^{-1}$ for $\mathrm{CDH}$ and 26.8 (15.5-35.0) $\mathrm{mL} \cdot \mathrm{kg}^{-1}$ for AWD. The median (range) PNL, CMAP amplitude and the coefficients of variation for the AWD and $\mathrm{CDH}$ patients are given in table 1. Supramaximality of MSPN was demonstrated by a plateau in CMAP amplitude at higher stimulus intensities for both the left and right phrenic nerves (fig. 3). There was no difference in left and right PNL, CMAP amplitude and TwPdi between AWD and $\mathrm{CDH}$ patients (fig. 4), There was, however, a significantly lower median (range) $\mathrm{cPI}$,max recorded in the $\mathrm{CDH}$ patients compared to the AWD patients (29.5 (14.1-46.6) $\mathrm{cmH}_{2} \mathrm{O}$ CDH versus 55.6 (30.6107.2) $\mathrm{cmH}_{2} \mathrm{O}$ AWD; $\left.\mathrm{p}=0.018\right)$.

All the patients with AWD except one had PNL within the normal range. In this patient the PNL was slightly prolonged both on the left $9.31 \mathrm{~ms}$ and the right $9.49 \mathrm{~ms}$. There was no difference in median (range) TwPdi between left 4.0 (2.97.0) $\mathrm{cmH}_{2} \mathrm{O}$ and right $4.4(2.9-6.8) \mathrm{cmH}_{2} \mathrm{O}$ hemidiaphragms. Of the patients with $\mathrm{CDH}, 2$ out of 5 had prolonged PNL (10.1 $\mathrm{ms}$ and $10.08 \mathrm{~ms}$ ). There was a trend for a prolonged PNL on the affected side (four left, one right sided) in the $\mathrm{CDH}$ patients, although this did not reach statistical significance; median (range) PNL on side with defect 8.9 (8.6-10.1) ms versus 6.0 (5.3-8.5) $\mathrm{ms}$ on side without the defect (fig. 5) $(p=0.0625)$. A similar pattern was seen with TwPdi (median (range) $1.4(0.9-3.4) \mathrm{cmH}_{2} \mathrm{O}$ side with defect versus 3.9 (3.34.8) $\mathrm{cmH}_{2} \mathrm{O}(\mathrm{p}=0.0625)$ side without defect (fig. 5).

The data for left and right diaphragm and phrenic nerve function were pooled in both the AWD and $\mathrm{CDH}$ patients and correlation analysis performed to examine the relationship between hemidiaphragm muscle contractility and phrenic nerve function and CMAP amplitude. A significant relationship was

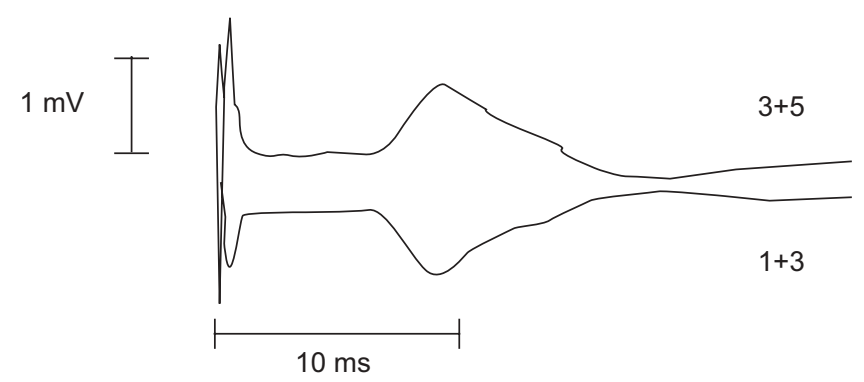

FIGURE 2. Representative diaphragm compound muscle action potential response following magnetic stimulation of the phrenic nerves showing equal and opposite responses from electrode pair $1+3$ below the electrically active centre of the diaphragm and pair $3+5$ above the electrically active centre of the diaphragm. 


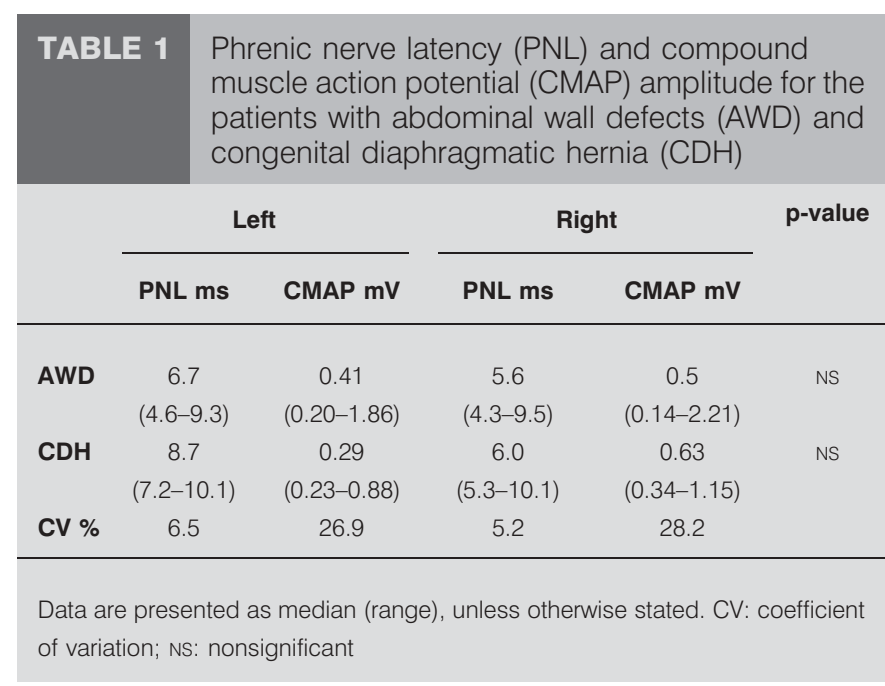

obtained between PNL and TwPdi in the $\mathrm{CDH}$ patients $(\mathrm{r}=0.8$; $\mathrm{p}=0.009$ ) (fig. 6).

\section{DISCUSSION}

These data suggest that an oesophageal EMG electrode used in conjunction with magnetic stimulation of the phrenic nerves can be used to assess phrenic nerve and diaphragm function in infants. There was a trend for prolonged phrenic nerve conduction time and reduced diaphragm contractility on the affected side in $\mathrm{CDH}$ which resulted in a statistically significant relationship between PNL and diaphragm muscle contractility.

Chest wall electrodes have been widely used to record the diaphragm CMAP with electrical stimulation of the phrenic nerves because of convenience and acceptability to subjects, a non-invasive approach being preferable in terms of patient comfort. There are, however, a number of disadvantages associated with the technique. The CMAP can be transmitted to distant surface electrodes by volume conduction [17]; a diaphragm CMAP has been recorded from contralateral chest wall electrodes [11] and from the centre of the abdomen [11] when using focussed electrical phrenic nerve stimulation. The short phrenic latencies reported by MoosA [18] using surface electrodes could have been due to a combination of high electrode position, and volume conduction with interference from extradiaphragmatic muscles such as latissimus dorsi, serratus anterior or pectoralis major [17, 18] a particular problem with magnetic phrenic nerve stimulation in which the stimulus is much less focussed than with electrical stimulation and there is a greater risk of brachial plexus co-activation [19]. LUO et al. [11] reported short latency CMAP responses when using surface electrodes with magnetic stimulation but not when recording from an oesophageal electrode. Diaphragm CMAPs recorded from chest wall surface electrodes can also be influenced by variable muscle to electrode distance due to the amount of subcutaneous fat, significantly affecting signal strength [20] and line frequency artefacts [21]. Also, there is no standardised method for positioning chest wall electrodes, making comparisons between subjects and studies difficult [21]. Improvements in amplifier design and signal processing have made it possible to distinguish the EMG signals from different respiratory muscles during spontaneous breathing

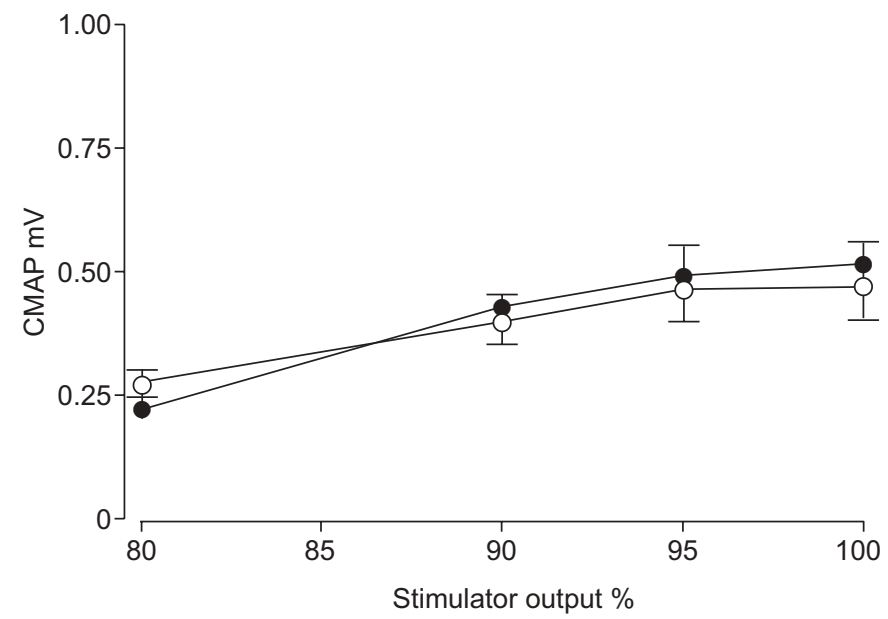

FIGURE 3. Mean \pm SE diaphragm compound muscle action potential (CMAP) responses versus stimulator output for left $(\bullet)$ and right $(\bigcirc)$ unilateral anterolateral magnetic stimulation in nine patients. Supramaximal stimulation was achieved as indicated by the plateau of CMAP amplitude with increasing stimulator output.

$[22,23]$. In contrast, the diaphragm CMAP recorded using an oesophageal electrode is not affected by obesity and less influenced by line artefact and contamination by other muscles $[11,19,20]$ leading to its increasing use as a clinical and research technique [12]. Disadvantages remain however, including discomfort and the risks of regurgitation and aspiration, as well as vagally mediated bradycardia during placement. No such adverse events were encountered during the current study.

In the current study, an oesophageal electrode was used to record the diaphragm CMAP. The phrenic nerve latencies recorded in the current study are similar to those reported previously [15, 24, 25]. Surface electrodes record activity from the costal component of the diaphragm while the oesophageal EMG records activity from the crural portion of the diaphragm [26]. Crural and the costal EMG activity is closely correlated in humans during respiratory tasks [27] but conduction times have been shown to vary by as much as $2 \mathrm{~ms}$ when measured using surface and oesophageal EMG electrodes [26]. However, CMAPs recorded with oesophageal electrodes are often larger with a clearly defined onset of electrical activity which can make estimation of PNL more accurate $[11,26]$. It is important therefore to define the technique by which the diaphragm CMAP was recorded. Similarly, the mode of phrenic nerve stimulation can also be important; CMAPs elicited by uAMS and recorded from chest wall surface electrodes can be unreliable due to contamination by extradiaphragmatic muscle activity. In adult patients with diaphragm paralysis, no obvious action potentials could be recorded from chest wall electrodes during focussed electrical stimulation (ES), whereas a small, short latency CMAP was recorded during uAMS [11]. No differences were observed in CMAP amplitude and PNL elicited by either ES or UAMS when recorded with an oesophageal electrode [13].

Transcutaneous electrical stimulation of the phrenic nerve has been most frequently performed [28], but the technique is uncomfortable and requires precise electrode placement to produce supramaximal stimulation, which in practice is often 

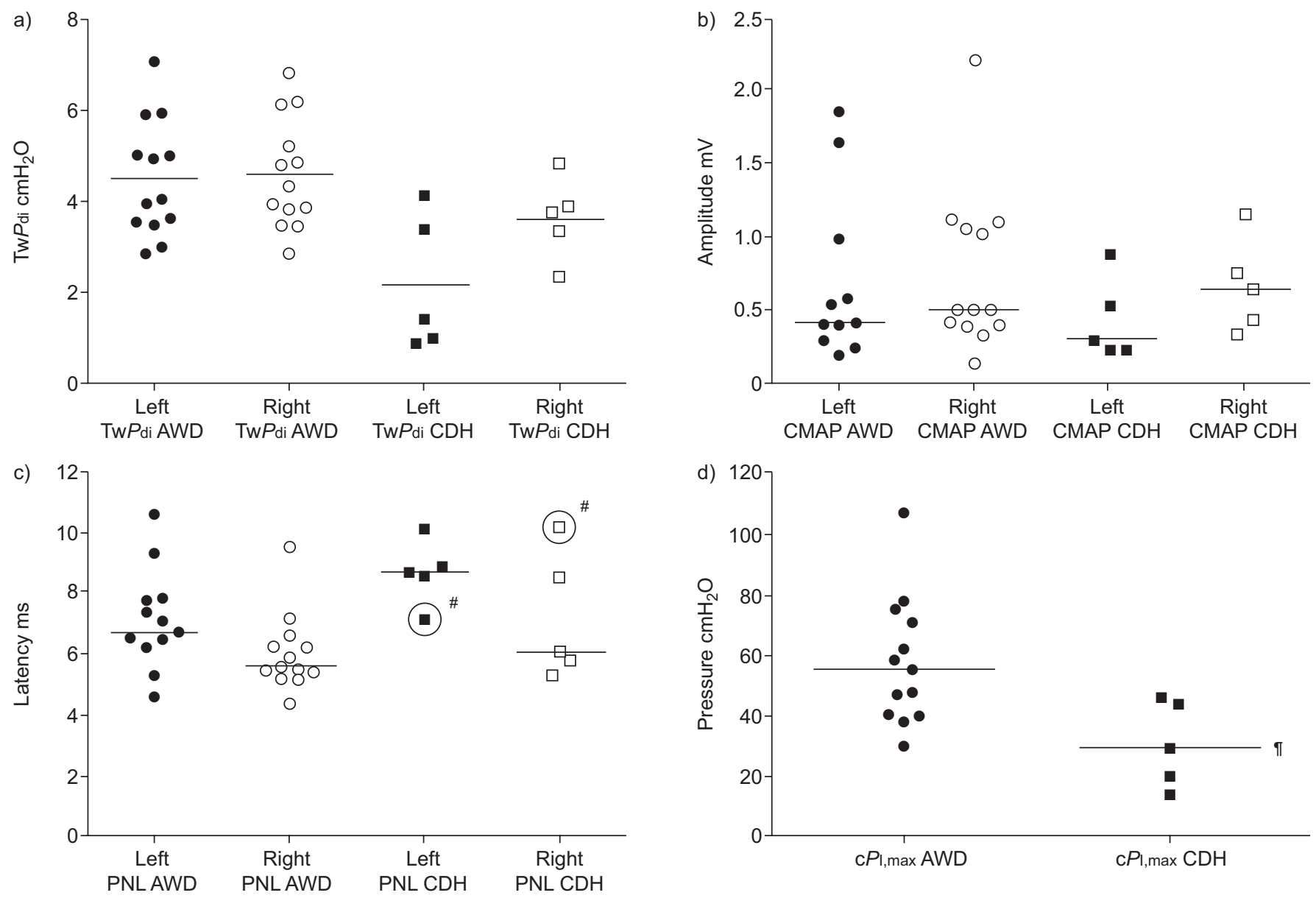

FIGURE 4. Individual data for the abdominal wall defects (AWD) and congenital diaphragmatic hernia (CDH) patients for left and right a) twitch transdiaphragmatic pressure (TwPdi), b) compound muscle action potential (CMAP) and c) phrenic nerve latency (PNL). Maximum inspiratory mouth pressure generated during crying (cPI,max).

—_: median value. "\#: CDH patient with left-sided defect. ": $p=0.018$.

difficult to achieve. Difficulty locating the phrenic nerves has been reported in adult patients with diaphragm weakness and required repeated stimulation over many minutes to obtain an accurate diagnosis [29]. Magnetic stimulation is painless and easily applied, the large surface area covered by the stimulating coils means the phrenic nerve can be easily and reliably stimulated. In the current study stimulations were well tolerated and the infants continued to sleep throughout the study session.

We have previously demonstrated supramaximality of MSPN in infants at 95\% stimulator output using TwPdi and in the current study we have confirmed these findings. Supramaximal stimulation of the phrenic nerves in adults has been demonstrated at $80 \%$ of magnetic stimulator output as assessed by TwPdi [30] and CMAP amplitude [11]. The magnetic coils and stimulators required to supramaximally stimulate the phrenic nerves in infants, however, are different to those routinely used in adults The site for stimulation in infants is smaller and the threshold stimulus intensities for exciting peripheral motor nerves using magnetic stimulation increases markedly below 2 yrs of age [22]. The plateau in CMAP amplitude also indicates there was no stimulation of the contralateral phrenic nerve. Such contralateral stimulation would have resulted in further increases in CMAP amplitude above 95\% stimulator output as more nerve fibres on the contralateral side were depolarised.

Standardising CMAP amplitude with surface electrodes has proved difficult due to large variations in CMAP amplitude between subjects $[26,31]$ possibly due to differences in chest wall thickness and difficulty in accurately positioning the electrodes, as well as maximally stimulating the phrenic nerve electrically [30]. Combining MSPN with an oesophageal electrode catheter should overcome these limitations. The oesophageal electrode array can be consistently located at the electrically active centre of the diaphragm by ensuring the diaphragm CMAPs, elicited from adjacent electrode pairs, are of equal amplitude but opposite polarity [32]. Using such an approach ensures a maximal and hence reproducible CMAP is recorded. The multipair electrode used in the current study has a span of $40 \mathrm{~mm}$, sufficient to cover the electrically active centre of the diaphragm. The array of metal ring electrodes on its surface are at the level of the crural diaphragm, the EMG activity of which is known to be representative of diaphragm activation as a whole [27].

In the current study the mean within occasion variability was $6.5 \%$ for PNL on the right and 5.2\% for PNL on the left. The 

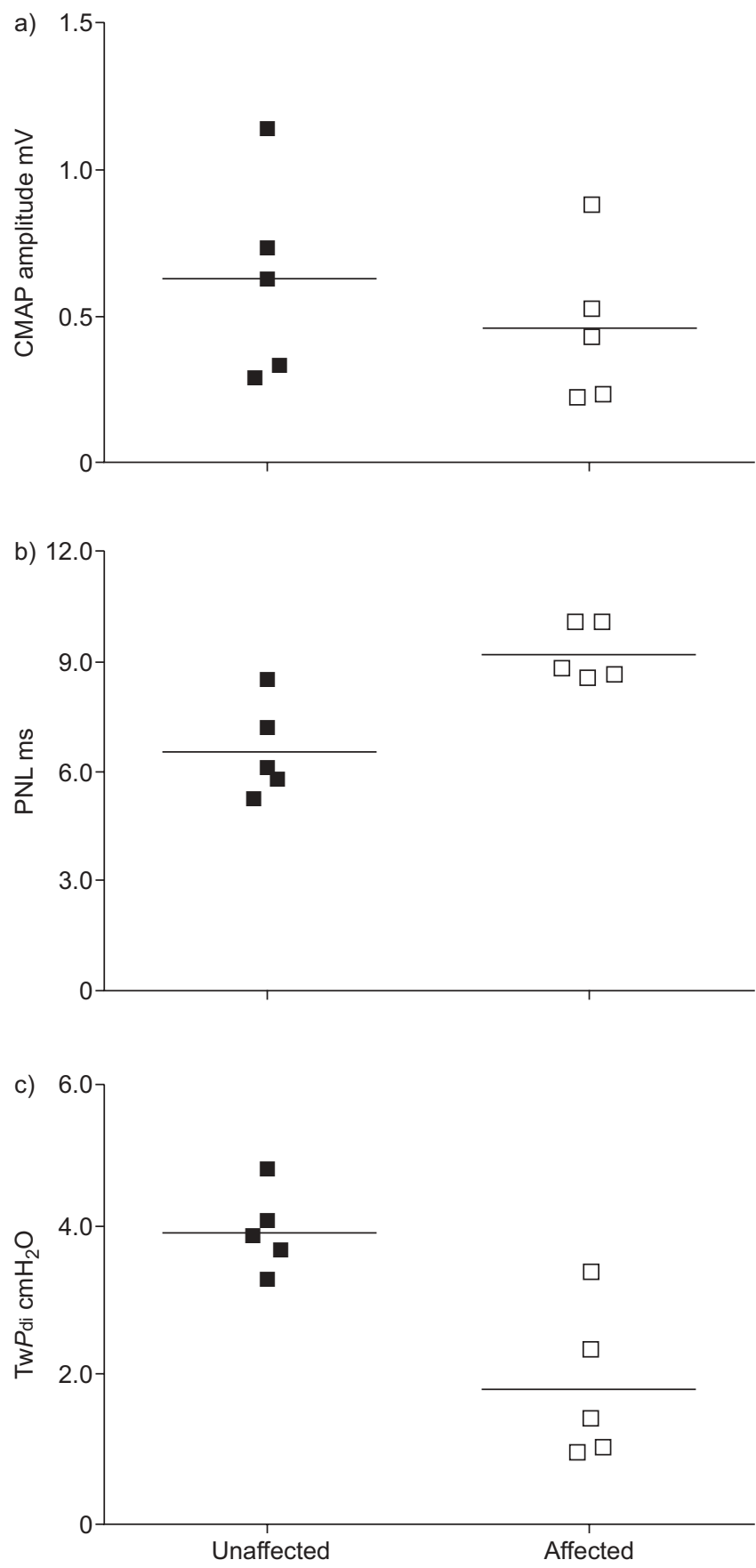

FIGURE 5. Individual data for a) compound muscle action potential (CMAP) amplitude, b) phrenic nerve latency (PNL) and c) twitch transdiaphragmatic pressure (TwPdi) for the congenital diaphragmatic hernia patients grouped according to the side on which the diaphragmatic hernia occurred.

coefficient of variation for CMAP was $33.8 \%$ on the left and $32.5 \%$ on the right. CMAP amplitude has not conventionally been reported due to difficulties associated with between occasion reproducibility of EMG measurements using surface electrodes as described above. Mean within occasion variability in adults for CMAP amplitude, using the same technique of magnetic phrenic nerve stimulation and an oesophageal EMG catheter, has been reported as $8.6 \%$ for unilateral magnetic stimulation [13] and 33\% for unilateral electrical

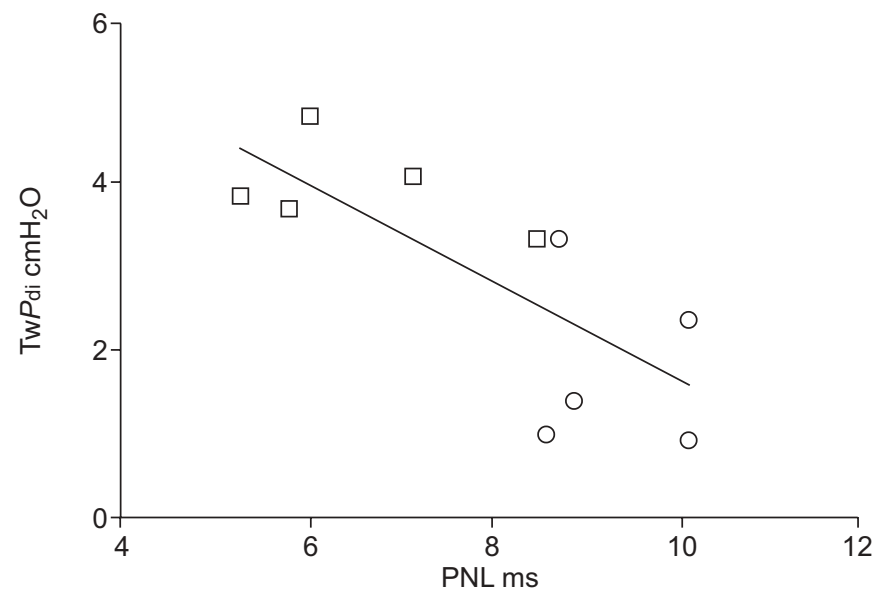

FIGURE 6. Spearman correlation analysis of the relationships between phrenic nerve latency (PNL) and twitch transdiaphragmatic pressure (TwPdi) for the congenital diaphragmatic hernia patients. $\bigcirc$ : hemidiaphragm with defect; $\square$ : hemidiaphragm without defect.

stimulation [32]. We attribute the large intra-subject, within occasion coefficient of variability in the current study to small changes in the relationship between diaphragm muscle fibres and the recording electrode that are likely to occur as a result of differences in expiratory lung volume when phrenic nerve stimulation did not occur precisely at end expiration. In the current study the point of end expiration was judged by careful observation of the infant's ribcage and abdominal movement, however, timing of phrenic nerve stimulation to occur at end expiration can be extremely difficult in infants with their high respiratory rates compared to adults. Measuring respiratory flow could have potentially improved the timing of phrenic nerve stimulation at end expiration, however the application of a facemask can disturb and arouse the infant making measurement difficult. Simultaneous measurement of EMG and intrathoracic and intra-abdominal pressures, possibly by the use of a combined catheter would provide guidance to timing of stimulation from the oesophageal pressure signal as well as giving simultaneous measurements of diaphragm contractility. Using both catheters simultaneously in the current study was not performed due to potential problems of damping and interference of the diaphragm EMG signal.

We assessed respiratory muscle strength using both volitional (cPI,max) and nonvolitional (TwPdi) techniques. $\mathrm{cPI}$,max provides a simple noninvasive, easy to perform, reproducible test of global respiratory muscle strength, the respiratory efforts being produced during crying are considered to be maximal [33]. The values of TwPdi in the current study are broadly comparable to those reported previously in these patient groups [6], particularly the reduction in TwPdi observed on the affected side in $\mathrm{CDH}$. The reduced diaphragm contractility in $\mathrm{CDH}$ may be as a result of low intra-abdominal pressure, affecting antenatal diaphragm development. It is unlikely that hyperinflation played a significant role as most of the infants studied had a low FRC, reflecting a degree of pulmonary hypoplasia. Although it did not reach significance, there was a trend for TwPdi to be lower and PNL longer on the affected 
side in the $\mathrm{CDH}$ patients and a significant relationship was observed between PNL and TwPdi in this group. Although we have previously shown that diaphragm force production in infants is impaired with $\mathrm{CDH}$ [6] we wished to examine whether there was associated phrenic nerve dysfunction. No histological data concerning the effects of $\mathrm{CDH}$ on the phrenic nerve are currently available for human infants. A reduction in axonal diameter could have potentially explained the prolongation of PNL but not the concomitant fall in TwPdi, as contractility reflects the number of nerve fibres stimulated and muscle fibre recruitment. Phrenic nerve injury during surgery to repair the defect may have resulted in prolongation of PNL and a reduction in TwPdi. It is also important to note the reduced musculature in the herniated hemidiaphragm, which in itself would potentially reduce TwPdi. The marked affect of hemidiaphragm herniation on PNL and TwPdi was not observed in CMAP amplitude, possibly due to the greater degree of variability observed in these data.

In conclusion, our data indicate that magnetic stimulation of the phrenic nerves in combination with an oesophageal electrode provides a robust technique to assess phrenic nerve function in infants and combining such measurements with those of pressure generation provides a comprehensive assessment of diaphragm function. In addition, impaired phrenic nerve conduction accompanies the diaphragm muscle dysfunction observed in infants with $\mathrm{CDH}$.

\section{STATEMENT OF INTEREST}

None declared.

\section{REFERENCES}

1 Gaultier C. Respiratory muscle function in infants. Eur Respir J 1995; 8: 150-153.

2 Ross Russell RI, Helps BA, Dicks Mireaux CM, et al. Early assessment of diaphragmatic dysfunction in children in the ITU: chest radiology and phrenic nerve stimulation. Eur Respir J 1993; 6: 1336-1339.

3 Rafferty GF, Greenough A, Dimitriou G, et al. Assessment of neonatal diaphragmatic paralysis using magnetic phrenic nerve stimulation. Pediatr Pulmonol 1999; 27: 224-226.

4 Sassoon CS, Zhu E, Caiozzo VJ. Assist-control mechanical ventilation attenuates ventilator-induced diaphragmatic dysfunction. Am J Respir Crit Care Med 2004; 170: 626-632.

5 Deem S, Lee CM, Curtis JR. Acquired neuromuscular disorders in the intensive care unit. Am J Respir Crit Care Med 2003; 168: 735-739.

6 Dimitriou G, Greenough A, Kavvadia V, et al. Diaphragmatic function in infants with surgically corrected anomalies. Pediatr Res 2003; 54: 502-508.

7 Dimitriou G, Greenough A, Endo A, et al. Prediction of extubation failure in preterm infants. Arch Dis Child 2002; 86: F32-F35.

8 Rafferty GF, Greenough A, Manczur TI, et al. Magnetic phrenic nerve stimulation to assess diaphragm function in children following liver transplantation. Pediatr Crit Care Med 2001; 2: 122-126.

9 Dimitriou G, Greenough A, Rafferty GF, et al. Effect of maturity on maximal transdiaphragmatic pressure in infants during crying. Am J Respir Crit Care Med 2001; 164: 433-436.

10 Rafferty GF, Greenough A, Dimitriou G, et al. Assessment of neonatal diaphragm function using magnetic stimulation of the phrenic nerves. Am J Respir Crit Care Med 2000; 162: 2337-2340.
11 Luo YM, Johnson LC, Polkey MI, et al. Diaphragm electromyogram measured with unilateral magnetic stimulation. Eur Respir J 1999; 13: 385-390.

12 Luo YM, Moxham J, Polkey MI. Diaphragm electromyography using an oesophageal catheter: current concepts. Clin Sci 2008; 115: 233-244.

13 Luo YM, Lyall RA, Lou Harris M, et al. Quantification of the esophageal diaphragm electromyogram with magnetic phrenic nerve stimulation. Am J Respir Crit Care Med 1999; 160: 1629-1634.

14 Hey EN. The relation between environmental temperature and oxygen consumption in the newborn baby. J Physiol (Lond) 1969; 200: 589-603.

15 Ross Russel RI, Helps B-A, Helms PJ. Normal values for phrenic nerve latency in children. Muscle Nerve 2001; 24: 1548-1550.

16 Milner AD, Marsh MJ, Ingram DM, et al. Effects of smoking in pregnancy on neonatal lung function. Arch Dis Child 1999; 80: F8-F14.

17 Markand ON, Kincaid JC, Pourmand RA, et al. Electrophysiologic evaluation of diaphragm by transcutaneous phrenic nerve stimulation. Neurology 1984; 34: 604-614.

18 Moosa A. Phrenic nerve conduction in children. Dev Med Child Neurol 1981; 23: 434-448.

19 Luo YM, Polkey MI, Lyall RA, et al. Effect of brachial plexus coactivation on phrenic nerve conduction time. Thorax 1999; 54: 765-770.

20 Beck J, Sinderby C, Weinberg J, et al. Effects of muscle-to-electrode distance on the human diaphragm electromyogram. J Appl Physiol 1995; 79: 975-985.

21 Aldrich TK, Sinderby C, McKenzie DK, et al. Electrophysiologic techniques for the assessment of respiratory muscle function: ATS/ERS statement on respiratory muscle testing. Am J Respir Crit Care Med 2002; 166.

22 Maarsingh EJ, Oud M, van Eykern LA, et al. Electromyographic monitoring of respiratory muscle activity in dyspneic infants and toddlers. Respir Physiol Neurobiol 2006; 150: 191-199.

23 Maarsingh EJ, van Eykern LA, Sprikkelman AB, et al. Respiratory muscle activity measured with a noninvasive EMG technique: technical aspects and reproducibility. J Appl Physiol 2000; 88: 1955-1961.

24 Raimbault J, Renault F, Laget P. Technique et resultats de l'exploration electromyographique du diaphragme chez le nourrisson et le jeune enfant. [Technique and results of the electromyographic exploration of the diaphragm in infants and young children.] Rev Electroencephalogr Neurophysiol Clin 1983; 13: 306-311.

25 Imai $\mathrm{T}$, Shizukawa H, Imaizumi H, et al. Phrenic nerve conduction in infancy and early childhood. Muscle Nerve 2000; 23: 915-918.

26 McKenzie DK, Gandevia SC. Phrenic nerve conduction times and twitch pressures of the human diaphragm. J Appl Physiol 1985; 58: 1496-1504.

27 Lourenco RV, Cherniack NS, Malm JR, et al. Nervous output from the respiratory center during obstructed breathing. I Appl Physiol 1966; 21: 527-533.

28 Ross Russell RI, Helps BA, Elliot MJ, et al. Phrenic nerve stimulation at the bedside in children; equipment and validation. Eur Respir J 1993; 6: 1332-1335.

29 Mier A, Brophy C, Moxham J, et al. Phrenic nerve stimulation in normal subjects and in patients with diaphragmatic weakness. Thorax 1987; 42: 885-888.

30 Mills GH, Kyroussis D, Hamnegard CH, et al. Unilateral magnetic stimulation of the phrenic nerve. Thorax 1995; 50: 1162-1172.

31 Swenson MR, Rubenstein RS. Phrenic nerve conduction studies. Muscle Nerve 1992; 15: 597-603.

32 Luo YM, Polkey MI, Johnson LC, et al. Diaphragm EMG measured by cervical magnetic and electrical phrenic nerve stimulation. J Appl Physiol 1998; 85: 2089-2099.

33 Dimitriou G, Greenough A, Dyke H, et al. Maximal airway pressures during crying in healthy preterm and term neonates. Early Hum Dev 2000; 57: 149-156. 